\title{
ANÁLISE COMPARATIVA ENTRE DOIS MÉTODOS DE OBTENÇÃO DE SÍLICA E ALUMINA EM MINÉRIO DE FERRO*
}

\author{
Márcio de Morais Tavares ${ }^{1}$ \\ Paulo Roberto Santos Dantas ${ }^{2}$ \\ Humberto de Sousa Silva ${ }^{3}$ \\ Willy Ank de Morais ${ }^{4}$
}

\section{Resumo}

A espectrometria de fluorescência de raios $X$ (FRX ou XRF) é uma das técnicas analíticas mais utilizadas em geoquímica. Na indústria mineral também se utiliza a espectrometria de absorção atômica (AA). A comparação de concentrações de sílica e alumina de oito amostras padronizadas de minério de ferro obtidas a partir das técnicas FRX e absorção atômica, constitui o objetivo deste trabalho. Foram realizadas análises dos mesmos padrões em outros dois laboratórios para reprodutibilidade dos resultados. Foram utilizados um espectrômetro FRX e um espectrômetro de absorção atômica para realização dos ensaios. As análises produziram resultados satisfatórios, com desvios médios de 0,502 para a sílica e 0,096 para a alumina.

Palavras-chave: Espectrometria; Raio-X; Absorção atômica; Minério de ferro.

\section{COMPARATIVE ANALYSIS BETWEEN TWO METHODS OF ATTAINMENT OF SILICA AND ALUMINA IN IRON ORE}

\begin{abstract}
The spectrometry of fluorescence of rays $X(F R X$ or $X R F)$ is one of the used analytical techniques more in geochemistry. In the mineral industry also the spectrometry of atomic absorption (AA). The comparison of concentrations of silica and alumina of eight standardized samples of iron ore gotten from techniques $F R X$ and atomic absorption constitutes the objective of this work. They had been carried through analyses of the same standards in others two laboratories for reprodutibility of the results. A spectrometer FRX and a spectrometer of atomic absorption for accomplishment of the assays had been used. The analyses had produced resulted satisfactory, with average shunting lines of 0,502 for silica and 0,096 for alumina..
\end{abstract}

Keywords: Spectrometry; X-Ray; Flame atomic absorption; Iron ore.

1 Doutorando em Engenharia Química (POLI - USP), MSc. Engenharia Mecânica, Engo Químico. Prof. Faculdade de Engenharia da UNAERP, Téc. da superintendência de redução da Usiminas Cubatão, SP, Brasil.E-mail: marcio2005@hotmail.com.

2 Engo Químico, Téc. em Química. Téc. de Assistência Técnica III da Usiminas - Cubatão, SP, Brasil. E-mail:paulo.dantas@usiminas.com.

3 Mestrando em Engenharia Mecânica, Engenheiro de Telecomunicações. Assistente técnico industrial da Usiminas - Cubatão, SP, Brasil.E-mail:humberto.sousa@usiminas.com.

4 Doutorando, MSc., Engo Metalurgista, Téc. em Metalurgia. Prof. Faculdade de Engenharia da UNISANTA, Consultor Técnico da INSPEBRAS. Santos, SP, Brasil. E-mail: willyank@unisanta.br.. 


\section{INTRODUÇÃO}

\subsection{Espectrometria de Fluorescência de Raios-X}

Um dos principais atrativos da XRF é a relativa simplicidade de preparação das amostras já pulverizadas. A fusão das amostras com fundentes e o posterior resfriamento produz vidros. Esta forma de homogeneização da amostra facilita a determinação de elementos maiores e menores ( $\mathrm{Na}, \mathrm{Mg}, \mathrm{Al}, \mathrm{Si}, \mathrm{P}, \mathrm{K}, \mathrm{Ca}, \mathrm{Ti}, \mathrm{Mn}, \mathrm{Fe}$ ). A preparação direta de pastilhas prensadas a partir das amostras pulverizadas também é muito usada, mas encontra aplicação mais frequente na determinação de elemento-traço [3]. Os limites de detecção da XRF convencional, da ordem de alguns até dezenas de ppm, não são uniformes para todos os elementos [5]. Elementos leves $(Z<10)$ não são analisados na XRF convencional e a baixa concentração de muitos elementos-traço (p.ex., metais nobres) em amostras geológicas comuns impede a sua determinação por esta técnica. A fluorescência de raio- $X$ dos elementos presentes numa amostra ocorre quando esta é atingida por raios $X$ oriundos de um tubo de raios $X$. Ao incidirem nos átomos da amostra, esses raios $X$ primários ejetam elétrons das camadas próximas do núcleo, conforme a Figura 1, que ilustra a excitação dos níveis eletrônicos internos, com a ejeção de um elétron da camada $\mathrm{K}$ e possibilidades de preenchimento da vacância com elétrons dos níveis mais externos, com a consequente emissão de raios $X$. As vacâncias assim criadas são imediatamente preenchidas por elétrons das camadas mais externas e simultaneamente há emissão de raios $X$ (fluorescentes ou secundários) cuja energia corresponde à diferença entre as energias dos níveis e subníveis das transições eletrônicas envolvidas.

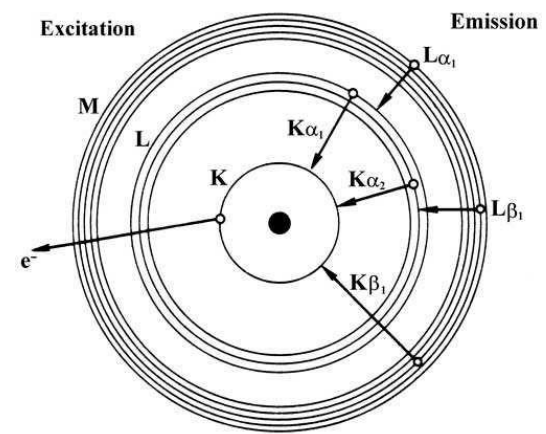

Figura 1. llustração da excitação dos níveis eletrônicos internos, com a consequente emissão de raios $\mathrm{X}$ e a notação correspondente.

Os níveis eletrônicos são denominados K, L, M, N, sequencialmente a partir do núcleo. Uma vacância na camada $\mathrm{K}$ pode ser preenchida por elétrons de diferentes subníveis das camadas $L$ ou $M$. Como consequência, há a emissão de radiação eletromagnética cuja energia corresponde à região dos raios $X$. Cada transição entre sub-níveis específicos, possui uma energia característica e por isto, uma denominação única. Por exemplo, a vacância da camada $\mathrm{K}$ pode ser preenchida por elétrons de dois subníveis da camada $L$, o que origina raios $X$ com dois valores de energia, Ka1 e Ka2 conforme mostrado na Figura 1.

Elétrons da camada $\mathrm{M}$ também podem ocupar a vacância da camada da $\mathrm{K}$ e tal transição dá origem a raios X Kß. Da mesma forma, vacâncias da camada $K$ são preenchidas por elétrons das camadas $\mathrm{M}$ e $\mathrm{N}$, e os raios $X$ característicos emitidos recebem denominações $L \alpha, L \beta$ com índices específicos [8]. 
As energias dos raios $\mathrm{X}$, emitidas em decorrência das transições eletrônicas, correspondem às diferenças de energia dos subníveis envolvidos. Na ilustração da Figura 2 há um diagrama dos níveis e subníveis energéticos do bário, com as respectivas energias (em $\mathrm{keV}$ ) indicadas à direita. Uma vacância de elétron na camada $\mathrm{K}$ pode produzir as cinco emissões $\mathrm{K}$ indicadas, cada uma delas com certa probabilidade de ocorrer e energia equivalente à diferença de energia da transição. As flechas indicam transições eletrônicas elétrons das camadas $L$ e $M$ para vacâncias nas camadas $\mathrm{K} \mathrm{e} \mathrm{L}$. As energias correspondentes dos níveis e/ou sub-níveis estão indicadas à direita. Por exemplo, a energia da transição Ka1 é dada pela diferença de energia da transição, isto é, EKa1=37,441-5,247=32,194 keV e a energia da transição Ka2 é EKa2=37,441-5,634=31,807 keV.

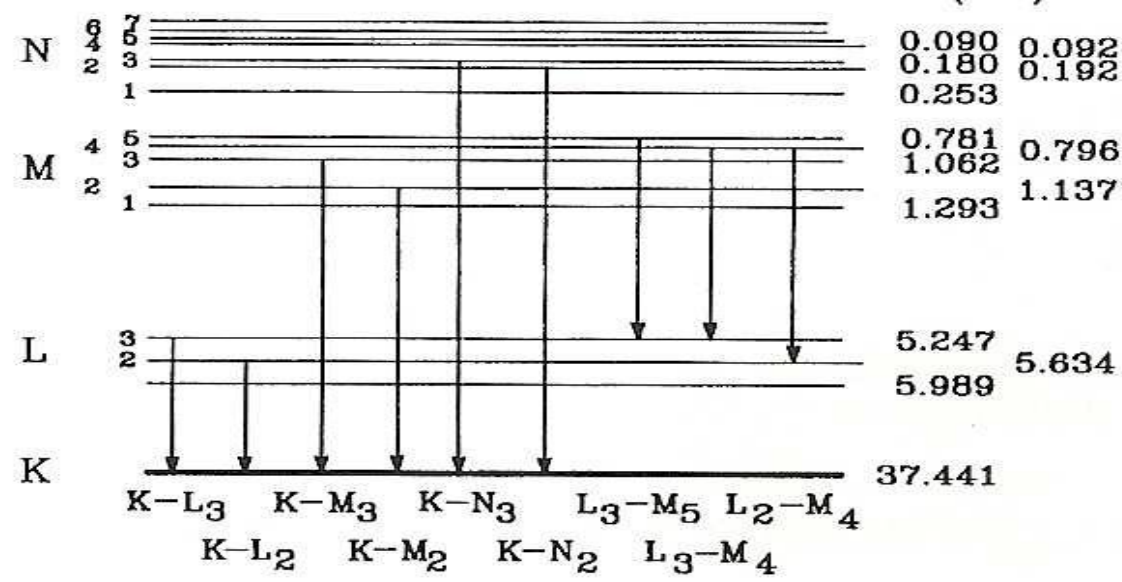

Figura 2. Diagrama dos níveis e subníveis energéticos do bário, com as respectivas energias (em keV) indicadas à direita.

Cada transição eletrônica tem certa probabilidade de ocorrer e, consequentemente, as linhas têm intensidades diferentes entre si. Por exemplo, a linha EKa1 tem o dobro da intensidade da linha EKa2. Para muitos elementos, a energia destas duas linhas é muito próxima, e não é possível medi-las separadamente. Nestes casos é observado um único pico, denominado Ka1,2 com energia intermediária entre aquelas das linhas separadas.

Cada tipo de átomo tem um espectro de raios $\mathrm{X}$ característico e único e, em geral, a energia da transição mais intensa é usada na análise.

A análise é realizada num espectrômetro de fluorescência de raios $X$, que contém a fonte de excitação, em geral um tubo de raios $X$, o porta amostras com o espécime, e os sistemas de dispersão, detecção e processamento de dados, conforme ilustrado na Figura 3.

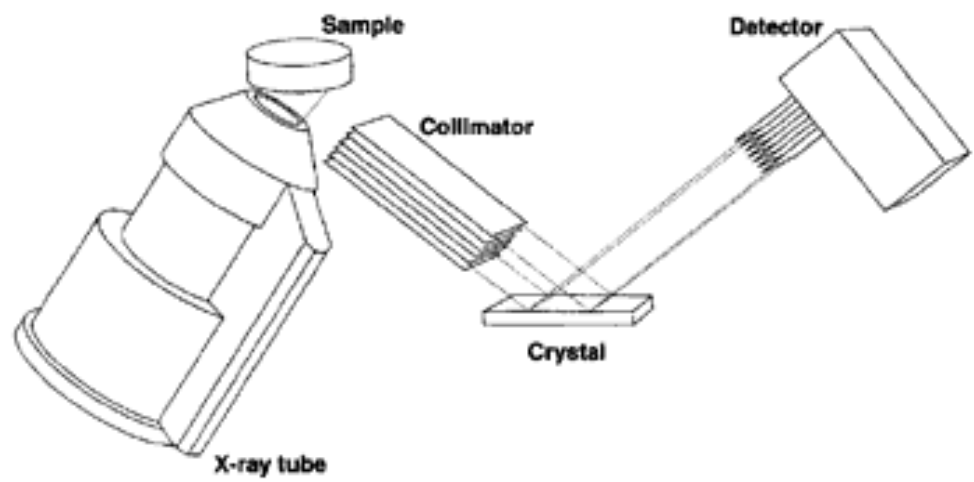

Figura 3. Arranjo instrumental de um espectrômetro de fluorescência de raios $X$. 
O tubo de raios $X$ é operado em condições que superem a energia crítica de excitação das linhas que serão usadas na medição dos elementos de interesse. Por exemplo, no caso do bário, a energia crítica de excitação do nível K é 37,441 keV. Portanto, para excitar o nível $\mathrm{K}$ do $\mathrm{Ba}$, o tubo de raios $\mathrm{X}$ deve ser operado com pelo menos 45 kV (20\% a mais que a energia crítica de excitação). Na Figura 4 há um esquema dos componentes um tubo de raios $\mathrm{X}$, cujo interior está sob vácuo.

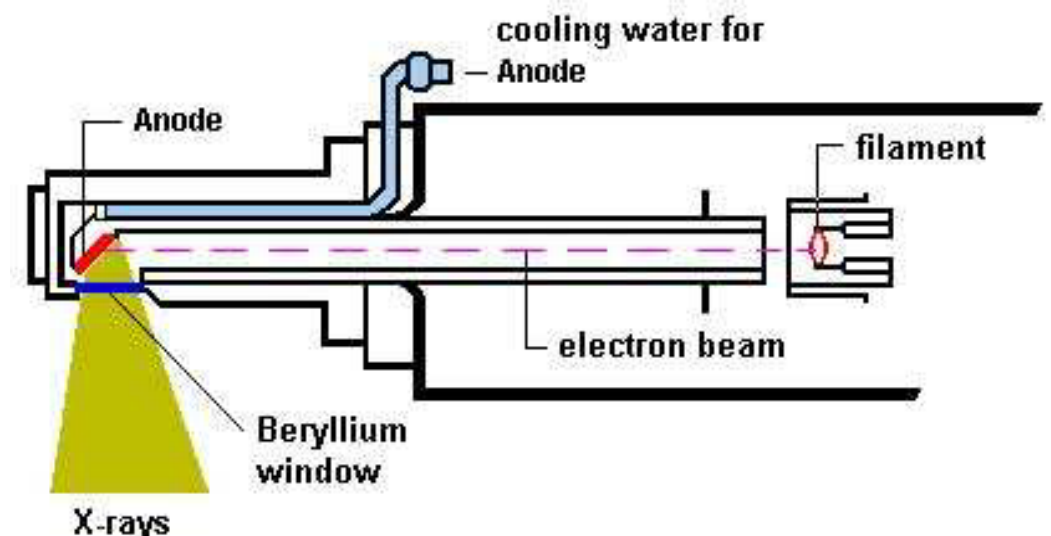

Figura 4. llustração dos principais componentes de um tubo de raios $X$.

O filamento, um fio de tungstênio, é o cátodo. Este, ao ser aquecido pelo fornecimento de corrente, libera elétrons, os quais são acelerados em direção ao ânodo, em função da potencial aplicado. A interação desses elétrons com o ânodo produz três tipos de efeitos. No primeiro, a desaceleração dos elétrons, produz um contínuo de raios $X$, com máximo de energia equivalente ao potencial de operação do tubo de raios $X$. Uma parte da energia dos elétrons incidentes no ânodo excita os níveis eletrônicos internos do metal do ânodo e produz raios $X$ característicos dele. Os raios $X$ saem pela janela de berílio. $O$ terceiro efeito é a produção de calor. A circulação de água refrigerada evita que o calor danifique o tubo de raios $X$. Nos tubos de raios $X$ usados na FRX, o ânodo metálico quase sempre é de ródio [17].

Os raios $X$ do tubo incidem na amostra e, por sua vez, também produzem vários efeitos. Deles, o mais relevante para a FRX são os raios $X$ característicos dos elementos presentes no espécime. Cada linha característica a ser medida é separada dos demais raios $X$ produzidos na amostra (outros $\lambda$ ), do mesmo elemento e dos demais elementos) pelo sistema de dispersão. $O$ sistema mais comumente utilizado para analisar amostras geológicas é o de dispersão de comprimentos de onda, que contém colimadores e cristais analisadores. Para um dado comprimento de onda a ser medido, há um colimador e um cristal adequados. Conforme ilustra a Figura 3, um colimador é constituído por uma série de placas paralelas. Os raios $\mathrm{X}$ que passam pelo colimador constituem um feixe paralelo, mas ainda de muitos comprimentos de onda. O comprimento de onda de interesse (isto é, de uma dada transição, de um elemento específico) é separado dos demais por um cristal, por difração. Esta decorre por dois fenômenos: espalhamento e interferência construtiva, ilustrados na Figura 5 [15]. 


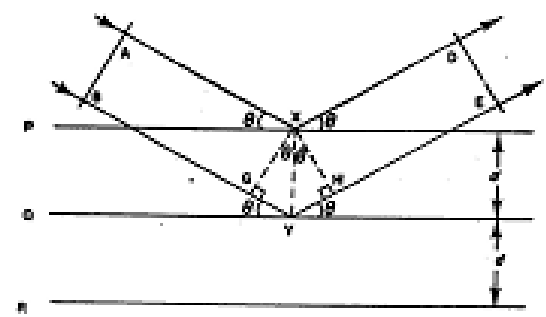

$$
\begin{aligned}
\mathrm{BYE} & =\mathrm{AXD}+(\mathrm{GY}+\mathrm{YH}) \\
\Delta \mathrm{GXY}, \operatorname{sen} \theta & =\mathrm{GY} / d \quad \therefore \quad \mathrm{GY}=d \operatorname{sen} \theta \\
\Delta \mathrm{YXH}, \operatorname{sen} \theta & =\mathrm{YH} / d \quad \therefore \quad \mathrm{YH}=d \operatorname{sen} \theta \\
\therefore \quad(\mathrm{GY}+\mathrm{YH}) & =2 d \operatorname{sen} \theta
\end{aligned}
$$

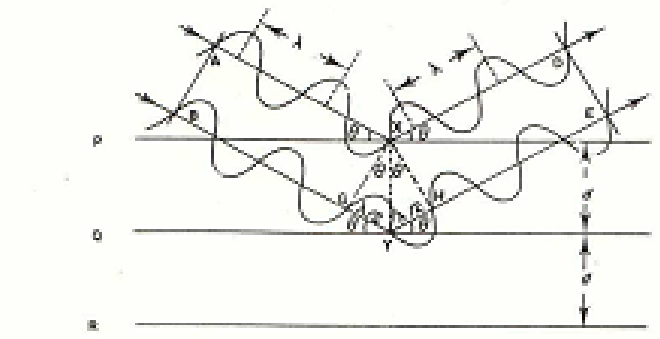

Condiçăo de Bragg : $2 d \operatorname{sen} \theta=n \lambda$, para $n=1$ $(\mathrm{G} Y+\mathrm{YH}=\lambda / 2+\lambda / 2)$

Figura 5. Difração de raios $X$, a partir do espalhamento de um feixe de raios $X$, com os planos de átomos de um cristal e a condição de Bragg para que ocorra a difração.

No lado esquerdo da Figura 5, dois raios paralelos incidem na face de um cristal. Um dos raios é espalhado pelo plano superficial de átomos segundo o ângulo $\theta$ e $o$ raio paralelo ao primeiro, é espalhado segundo o mesmo ângulo $\theta$ pelo primeiro plano interno de átomos paralelo ao superficial. Estes planos de átomos constituem uma família de planos cristalinos, separados entre si pela distância $d$. O ângulo de emergência dos dois raios é o mesmo de incidência, isto é, $\theta$. A condição para que os dois raios interfiram entre si de forma construtiva é que as ondas emergentes estejam em fase. Para que isto ocorra, a diferença de percurso dos dois raios deve ser igual a um número inteiro de comprimentos de onda. $E$ esta condição é dada pela Lei de Bragg, $n \lambda=2 d \operatorname{dsen} \theta$, onde $\mathrm{n}=$ ordem de difração, $\lambda=$ comprimento de onda dos raios $\mathrm{X}$, $d=$ espaçamento entre os planos de reflexão do cristal, $\theta=$ ângulo entre a superfície da amostra e o cristal. Depois de difratados, os raios $X$ chegam aos detectores, que também estão a um ângulo $\theta$ do cristal. $O$ ângulo total entre o espécime e o sistema de detecção é $2 \theta$. Nos detectores, os fótons são convertidos em sinal elétrico, o qual é amplificado e processado. O sinal medido é dado em contagens por segundo. Em um WD-XRF são usados vários cristais, conforme a tabela do exercício distribuído durante a aula, de forma que todos os comprimentos de onda dos elementos analisáveis sejam passíveis de medição [11].

\subsection{Espectrometria de Absorção Atômica}

\subsubsection{Fundamentação teórica}

A luz branca é a radiação em vários comprimentos de onda que nós percebemos como um conjunto de cores. O olho humano tem sensibilidade ás radiações de comprimento de onda que variam de 400 a $760 \mathrm{~nm}$. Cada fração desse comprimento é percebida pela nossa visão como uma cor. Violeta de 400-450 nm, azul de 450-500 nm, verde de 500-570 nm, amarelo de 570-590 nm, laranja de 590-630 nm e vermelho de 620$760 \mathrm{~nm}$ [13]. As frações acima de $760 \mathrm{~nm}$ são chamadas de infravermelho e as abaixo de $400 \mathrm{~nm}$ de ultravioleta. A percepção de cor de uma amostra, material ou composto depende de como este se comporta ao receber a incidência da luz visível [9]. Se um dado material, por exemplo, absorve todos os comprimentos de onda exceto aqueles próximos ao vermelho, nós o reconheceremos como sendo vermelho, do mesmo modo se ele absorve todos os comprimentos de onda, nós o perceberemos como preto. A faixa visível é apenas uma porção do espetro eletromagnético, que vai de 10$14 \mathrm{~m}$ a $108 \mathrm{~m}$ [13]. A espectrofotometria lida com os comprimentos de $185-400 \mathrm{~nm}$ e 760-1500 nm, enquanto a calorimetria lida com os espectros da região do visível. As 
cores são normalmente geradas por um reagente ou por um composto já presente na amostra que se deseje analisar [14]. Quase sempre a concentração dessa substância pode ser media pela intensidade da cor em um comprimento de onda especifico e característico daquele composto. Essa medição é feita comparando-se a intensidade da coloração de uma amostra que contenha o composto e da qual a concentração seja conhecida com a intensidade de coloração da amostra. As bandas nas quais são medidas as intensidade tem quase sempre menos de $1 \mathrm{~nm}$ de largura [4]. Os métodos espectrofotométricos e colorimétricos são úteis na determinação de concentrações tão baixas quanto 1-2\%. As ondas são descritas como função de comprimento de onda (lambda $\lambda$ ), que é a distância entre dois pontos da mesma fase em ondas que se sucedem dado em $\mathrm{cm}$, o número de onda ( $v$ - 'ni'), que é o número de ondas contidas em $1 \mathrm{~cm}$ e a frequência (v/c) é o número de ondas em 1 segundo. Elas se relacionam da seguinte forma:

$$
1 / \lambda=v=v / c
$$

Sendo: c - a velocidade da luz no vácuo ou $3 \times 10^{8} \mathrm{~m} / \mathrm{s}$.

\subsubsection{Equipamentos}

Os principais componentes dos instrumentos que medem absorção de radiação, seja ultravioleta, visível ou infravermelho, são: fonte, seletor de comprimento de onda, recipiente para amostras, transdutores de radiação e processador de sinal.

\subsubsection{Absorção da radiação}

A absorção da radiação Ultravioleta-Visível (UV-Vis) se dá nas espécies atômicas ou moleculares (M). A lâmpada para emissão é mostrada na Figura 6 e essa absorção ocorre da seguinte forma. Um fóton hv incide na espécie que é excitada até o estado $\mathrm{M}^{*}\left(\mathrm{M}+\mathrm{hv}=\mathrm{M}^{*}\right)$. Como o tempo de vida dessa espécie excitada é muito baixo, com cerca de $10^{-8}$ a $10^{-9}$ segundos, a formação dessa espécie não traz efeitos à concentração do analito. O decaimento da espécie excitada libera calor $\left(M^{*}=M+\right.$ calor), que gera uma perturbação térmica, porém tão pequena que o sistema como um todo praticamente não percebe essa mudança. Só existe alteração no sistema quando há decomposição fotoquímica, pois nesses casos a concentração é constantemente alterada com a incidência do feixe de radiação. A radiação absorvida é normalmente fruto da excitação dos elétrons de ligação, nas moléculas, ou dos elétrons da camada d, nos íons metálicos. De maneira geral, a absortividade molar $\varepsilon$ varia de 0 a $105 \mathrm{~L} /(\mathrm{mol} . \mathrm{cm})$ [7]. O máximo de absorção $\varepsilon$ é dependente da concentração, da probabilidade de transição energética $P$ e da seção transversal $A$.

$$
\varepsilon=8,7 \times 10^{-19} \mathrm{PA}
$$

A área da seção de uma molécula ou íon é de, normalmente, $10-15 \mathrm{~cm}^{2} / \mathrm{mol}$ e as probabilidades de transição eletrônicas variam de 0 a 1. Transições eletrônicas proibidas ocorrem menos frequentemente e tem probabilidades inferiores a 0,01 , gerando $\varepsilon$ também menores que 103. Elas são consideradas de baixa intensidade para o uso de absortividade [16]. Nos compostos inorgânicos as absorções se dão em comprimentos de onda relativos a excitação dos elétrons não ligantes, normalmente da camada d ou f. A maioria dos elementos do primeiro e segundo grupo absorvem radiação na região do visível em pelo menos um dos seus estados de oxidação. Daí o motivo da maioria das soluções desses íons serem coloridas [2]. As energias absorvidas, e consequentemente os comprimentos de absorção, dependem do 
ligante, do número de oxidação e do íon metálico, pois normalmente estes fatores é que influenciam as energias necessárias e a transição eletrônica do elétron dos orbitais d e f preenchidos e não preenchidos [1]. Íon dos lantanídeos e actinídeos tem bandas mais estreitas porque as transições se dão nos orbitais f. Por outro lado as transições dos elétrons da camada f são menos dependentes dos ligantes que aquelas das camadas $d$, uma vez que a camada f está mais afastada da camada de valência do átomo [6].

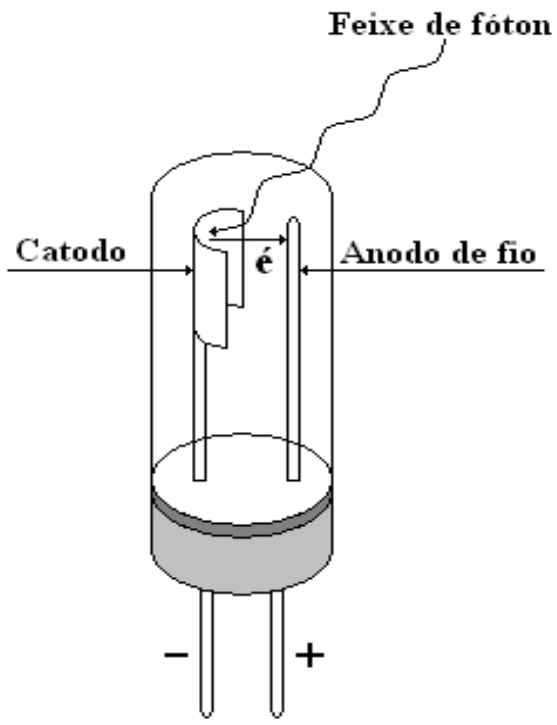

Figura 6. llustração dos principais componentes de um tubo de raios $X$.

\section{MATERIAIS E MÉTODOS}

\subsection{Análise dos Padrões por FRX}

Foi pesada em balança analítica aproximadamente $20 \mathrm{~g}$ da amostra e, após isso, essa foi transferida para a panela de pulverização; a amostra foi pulverizada e transferida para o briquete, depois prensada e levada ao Raio-X; foi analisado o padrão de aferição, limpado o K-7 e acoplado a amostra adequadamente no mesmo; foi posicionado o K-7 na base do braço hidráulico de transporte de amostra; o computador foi programado de acordo com o método; o braço hidráulico foi acionado e levado o K-7 com a amostra acoplada ao equipamento; foi aguardado o término da análise e registrado os valores da composição química registrados na tela do computador.

\subsection{Análise dos Padrões por Absorção Atômica}

O equipamento SPECTRAA 220 FS e seu respectivo software foram ligados; as válvulas internas dos gases foram abertas e ligado o sistema de exaustão; foi acendido a chama, e após a otimização dos elementos, deu-se partida na análise. Foi colocado a solução matriz e logo após, o padrão de calibração, acompanhando a formação da curva; foi colocado o balão volumétrico contendo a amostra assim que o aparelho solicitou; acompanhou-se a curva de análise da amostra e anotou-se os valores indicados na tela do computador. 


\section{RESULTADOS E DISCUSSÃO}

Através dos procedimentos experimentais, obteve-se uma série de dados, nos quais permitiu uma avaliação do erro entre as duas técnicas, pelo método de desvio simples.

Tabela 1. Resultados de análise de sílica por FRX e por absorção atômica.

\begin{tabular}{ccc}
\hline Padrão & $\boldsymbol{R} \boldsymbol{X}$ & $\boldsymbol{A b s o r c ̧ a ̃ o ~}$ \\
\hline PAD 01 & 2,50 & 2,99 \\
\hline PAD 02 & 4,08 & 4,81 \\
\hline PAD 03 & 6,70 & 7,37 \\
\hline PAD 04 & 8,41 & 9,68 \\
\hline PAD 06 & 17,25 & 17,63 \\
\hline PAD 7592 & 6,00 & 6,68 \\
\hline PAD 152 & 5,57 & 6,01 \\
\hline PAD 158 & 4,09 & 4,89 \\
\hline
\end{tabular}

A figura 7 mostra as concentrações de sílica em minério de ferro obtidas através das técnicas FRX e absorção atômica e as concentrações de sílica obtidas através das técnicas FRX em três laboratórios, respectivamente.

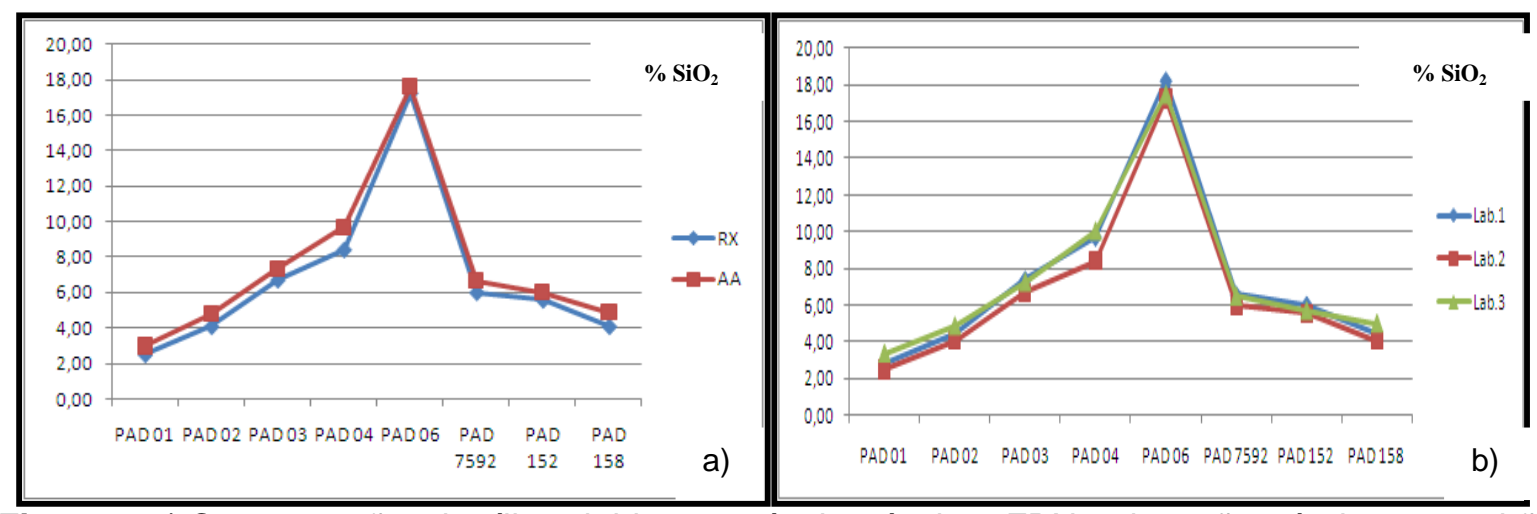

Figura 7. a) Concentrações de sílica obtidas através das técnicas FRX e absorção atômica em padrões de minério de ferro e b) Concentrações de sílica obtidas através da técnica FRX em diferentes laboratórios.

Tabela 2. Resultados de análise de alumina por FRX e por absorção atômica.

\begin{tabular}{ccc}
\hline Padrão & RX & Absorção \\
\hline PAD 01 & 0,480 & 0,577 \\
\hline PAD 02 & 0,925 & 1,104 \\
\hline PAD 03 & 1,025 & 1,126 \\
\hline PAD 04 & 2,345 & 2,373 \\
\hline PAD 06 & 1,630 & 1,673 \\
\hline PAD 7592 & 1,565 & 1,786 \\
\hline PAD 152 & 0,850 & 1,082 \\
\hline PAD 158 & 0,835 & 1,018 \\
\hline
\end{tabular}

A figura 8 mostra as concentrações de alumina em minério de ferro obtidas através das técnicas FRX e absorção atômica e as concentrações de alumina obtidas através das técnicas FRX em três laboratórios, respectivamente. 


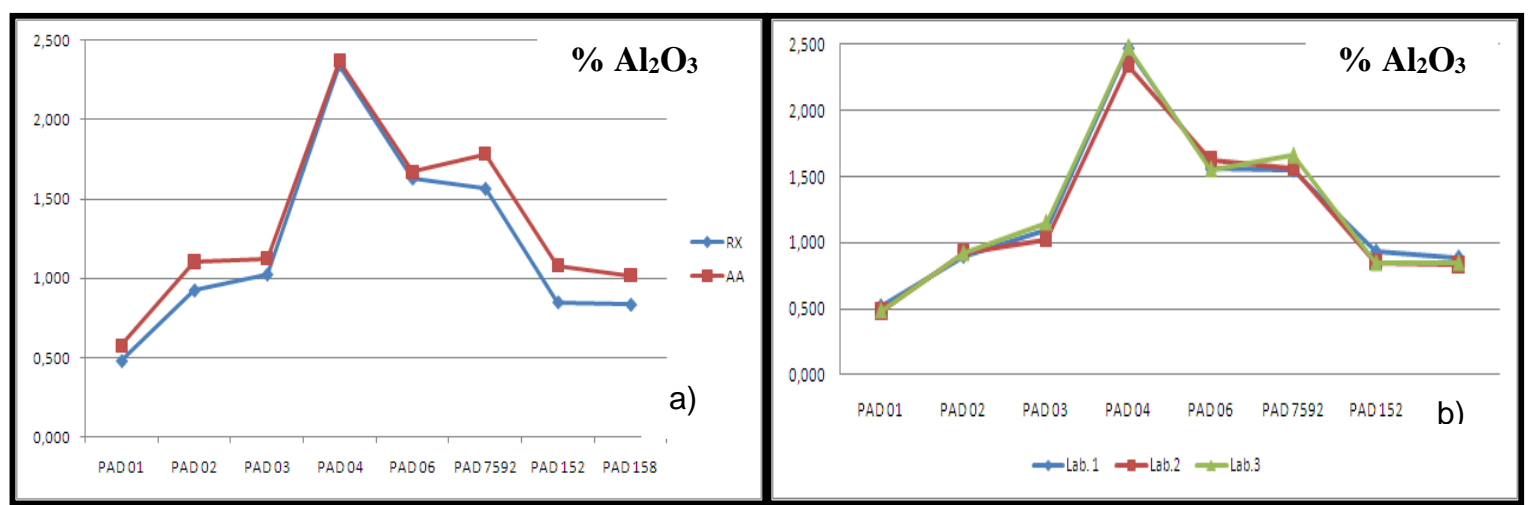

Figura 8. a) Concentrações de alumina obtidas através das técnicas FRX e absorção atômica em padrões de minério de ferro e b) concentrações de alumina obtidas através da técnica FRX em diferentes laboratórios.

Como atenuante, destaca-se que os dados provenientes das análises de sílica pelo método FRX são menores que os dados provenientes das análises pelo método de absorção atômica. O menor desvio padrão é referente ao padrão 06 (PAD 06) com 0,629 e o maior refere-se ao padrão 04 (PAD 04) com 0,898.

Os resultados da reprodutibilidade interlaboratorial referente às concentrações de sílica apresentaram desvios padrão médio de 0,451 entre os laboratórios LAB.1, LAB.2 e LAB.3.

No que se referem à alumina, os dados provenientes das análises por FRX também mantiveram menores valores em relação às análises por $A A$. $O$ menor desvio padrão é referente ao padrão 04 (PAD 04) com 0,020 e o maior refere-se ao padrão 152 (PAD 152) com 0,164.

Os resultados da reprodutibilidade interlaboratorial referente às concentrações de alumina apresentaram desvios padrão médio de 0,043 entre os laboratórios LAB.1, LAB.2 e LAB.3.

\section{CONCLUSÃo}

De um modo geral, as análises dos padrões de minério de ferro utilizando os dois métodos analíticos, permitiu concluir que a média dos desvios das concentrações é da marca de 0,483 para sílica e de 0,096 para a alumina. Em análise comparativa dos métodos estudados, foi possível evidenciar as concentrações reduzidas tanto de sílica quanto de alumina, quando a técnica FRX foi utilizada.

À luz da situação atual, temos as seguintes considerações preliminares:

a) O comportamento das concentrações de sílica e alumina pelo método FRX indica redução em todas as amostras padronizadas, fruto provável do tempo de operação do equipamento (mais de trinta e cinco anos) e o modelo ser obsoleto.

b) As análises realizadas em paralelo de acordo com os métodos descritos nos itens 2.1 e 2.2 conseguiram os resultados esperados.

c) A avaliação estatística preliminar das informações de análise provenientes dos equipamentos de FRX e AA não indicaram claramente as causas dos desvios, exigindo um maior tratamento dos dados.

Conforme descrito na introdução deste trabalho, a FRX é uma técnica na qual se mede a intensidade dos fótons emitidos por um determinado elemento, quando o mesmo é submetido a uma fonte de energia específica. Quando o equipamento informa a quantidade de intensidade, faz-se uma relação concentração $x$ intensidade, sendo que a concentração é conhecida e foi determinada por um método primário (via úmida ou 
absorção atômica). Apesar de a técnica AA ser mais confiável, podemos concluir que a média dos desvios padrão não apresenta erro significativo e que se podem utilizar os dois métodos de análise com um grau de confiança específico.

Sugerem-se, para continuidade deste trabalho, que se modele um fator de correção para otimização dos resultados.

\section{REFERÊNCIAS}

1. ATKINS, PETER; JONES, LORETTA. Princípios de Química, 3를ição, 2007, Editora Bookman.

2. BACCAN, NIVALDO; AANDRADE, JOÃO CARLOS DE; GODINHO, OSWALDO E. S.; BARONE, JOSÉ SALVADOR. Química Analítica Quantitativa Elementar, $3^{2}$ edição, 2001, Editora Blucher.

3. BERTIN, E. P. Principles and practice of $x$-ray spectrometric analysis. New York, Plenum, 1970.

4. GINÉ-ROSIAS, Maria Fernanda. Espectrometria de Emissão Atômica - ICP: Plasma Acoplado Indutivamente. Piracicaba. CENA/USP. 1998.

5. JENKINS, R. An introduction to x-ray spectrometry. London, Heyden, 1974.

6. MENDHAM, J.; DENNEY, R. C.; BARNES, J. D.; THOMAS, M. Análise Química Quantitativa, 6⿳亠丷厂 Edição, 2002,Editora LTC.

7. MONTASER, A.,Inductively Coupled Plasmas in Analytical Atomic Spectrometry. New York. VCH Publishers, Inc. 1992

8. MÜLLER, R. Spectrochemical analysis by x-ray fluorescence. New York, Plenum, 1972.

9. OHLWEILER, Otto Alcides. Fundamentos da Análise Instrumental. LTC Editora.1980.

10. Revista Analytica. Espectrometria de Emissão Óptica com Plasma Induzido por Laser (LIBS) - Fundamentos, aplicações e perspectivas. № 24. 2006.

11. SALVADOR, Vera Lúcia Ribeiro. Introdução à técnica de espectrometria de fluorescência de raios $x$. Shimadzu.

12. SKOOG, D. A. Fundamentals of Analytical Chemistry. 8 $8^{\mathrm{a}}$ Edição. Canadá. Editora Thomson.2004.

13. SKOOG, D. A. Principles of Instrumental Analysis. 3를 Edição. Estados Unidos da América. Editora Saunders College Publishing. 1985.

14. SLICKERS, K.A. Spectrochemical Analysis in the Metallurgical Industry. Pure \& Appl. Chem. 1993.

15. TERTIAN, R. AND CLAISSE, F. Principles of quantitative $x$-ray fluorescence analysis. London, Heyden, 1982.

16. VOGEL, A. I., Análise Química Quantitativa. Tradução: Horácio Macedo. 5ª edição. Rio de Janeiro. LTC. 1992.

17. WILLIAMS, K.L. Introduction to x-ray spectrometry. London, Allen \& Unwin, 1987. 